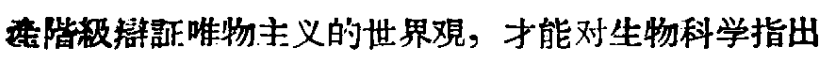
正确道路。我們相信在这方面社会主义科学事業必然 將有無限深远的㓣造前途，馬克思主义哲学也將由于 这方面的和广义的物理科学方面的工作扭鴐齐駘，獲
得更加丰富的磁痕。

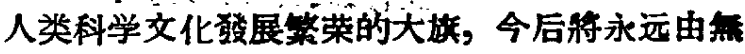

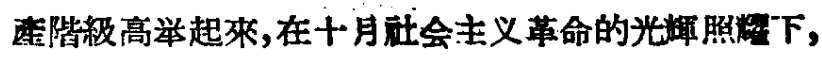
满怀信心地大步前進!

\title{
学㛭苏联先進經驗 努力赶上世界水平
}

\section{張 勁 夫}

(中國科学院副院展)

当我們大家正在热烈㦄呮荕联十月革命四十週年 紀念这一龦大節日的时候，我們同时让逢着苏联科学 上的大節日，这就是苏联在十月四日發射出了人类歴 史上第一顆人造地球衛星。全世界的科学工作者都在 热烈談論这件票，实际上豈但科学傢們在談論，政治 家、軍事家們以及关心人类前途的普通人們也在热烈 談論着。

現在差不多凡是睜着淑腈看事实的人，㲅不得不 承就, 这是一件偉大創䋃, 是具有原史意义的科学事 件，它标誌着科学成就的一个新紀元。当然也有不願 或不敢睜着眼睛看事实的人，例如美國海察作战参謀 银貝奈特，竟瞎說这 “只不过是一塄铁，几乎任何人

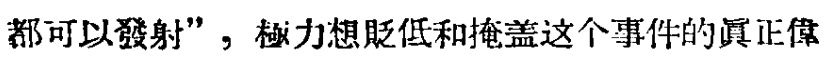
大噫义。可是这证合乎中國的一句古活：丳实滕于雄

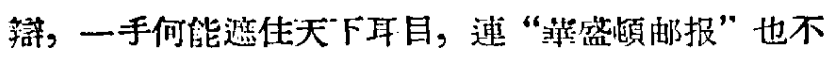
得不在社諭中吃着苦樂似地承認: “从一开头, “衛 星” 就是一个偉大的科学成就。这里任何想要低估或 忽悓它的趋势，只会使这个成就更加突出。”世界上 誠实和证直的科学家，無不在为这件創举贊美称鹿， 关心人类進步事業和爱好和吃的人們，都在为此欢 呼; 至于“一小撮死守熋断資本利谷的人，过去想用所

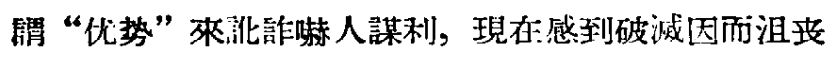
以至惶恐，这父有忆么办法呢?

这几年來，苏联在科学技術方通已有許多光辉成 就震动了世界。例如，苏联科学家首先在工業中利用 原子能，于 1954 年建立了世界第一个原子能發电站。 䓜泱第一艘裝有原子能發动机的破冰船將在今年队下 水,这艘破冰船能够航行兩三年而不必入港添加然料。 获联已經建成一百億电子伏特的粒子加速器，正在設 計五百境电子伏特的粒子加速器。苏联 “㨽-104”噴 气客机到过各國，被認为是世界上最好的噴气飛机。 至于最近發射成功的人造地球衛星，則是許多光輝成 就中更为突出的成就，因为“徨星”的發射成功，正如 托布切夫院士在談話中指出: 不是某一閏科学的勝 利，而是物理学、化学、数学、喷气技街、無緎电技 街和点他部門科学技術的勝利。
我們國內有些右派分子有时却別有用心地惡毒地 誹謗苏联，散布对茫联的不㴖情緒。科学界的右派分 子在進行这种誹謗时，常常是用誇耀美國的科学技術 先進，䏠低苏联的科学技街水平的手法，來企圖引起 人們对苏联的䡉梘和疏远，甚至挑㢸对苏联的不㴖。 有些中了“美國月亮好”的毒的人，对右派分子这种筐 曲誹謗, 有时也缺少防疫力,多少也受到一些傅深。現 在看看事实究竟怎皏呢? 过去的事实和最近的事灾,

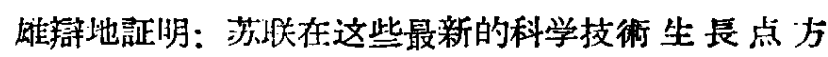
佰，是稳居世界第一位和走在科学最發达的瓷本主义

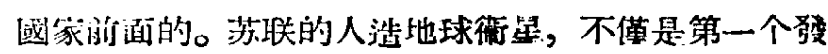
射成功，而且大家公認比美國老早就大疑宣傅而却义 迟迟發不出去的人造衛星妿优越得多。赫鲁墝夫同誌 在和賴斯頓談話中說: “如果美國今天还沟有火箭的 話, 那允將來你們也会有的, 因为科学在不断發展源。 对苏联來說也是一样: 如果你們有的什么东西积們今 天还沟有，那么我們將來会有的。”我們說茄联科学 技術走在資本主义國家的前面，並不是铞不－切方湎 都䂏过資本主义國家，美國在某些科学拔衙方通水本 是高的，我們社会主义陣营國家要努力趐上; 但从上 迅最新的科学技術生長点的成就來看, 荕联是稳步地 走在美國前面了。苏联之.所以能發射人造衛攵, 是因

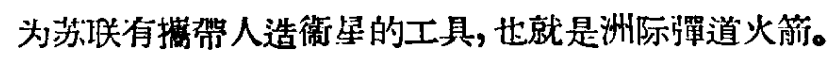
美國为什么現在还不能發射人造衙㚅呢? 也就是因为 美國没有洲际彈道火箭，如果有的話，也是可以䡒而 易举地放出人造衙星的。对于正曲和怀疑苏联科学技 術成就的人，人造地球衛星發射的成功，这个 “小小 的月亮”，不能不是一副清醒刘。

科学院和科联、科普最近召开了一次人造地球衛 星座談会, 到会的許多科学家發表了很好的意胃。特 别是有些科学家, 就其学科專業, 談了人造地球衡星 的發射成功对于今后有关学科的科学研究工作的傽大 影响和开辟新紀元的意义，使我們有更明确的認職和 更梁刻的体会。我現在想着重从这件事联系起來談一

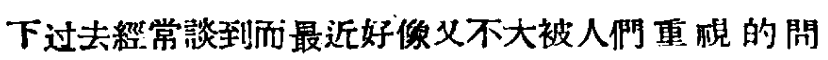
题，郎是在我們磨沅苏联十月革命四十祘年紀念的革 
命節日和同时庭賀人造地球箱星墢射成功的科学節日 的时候，我們要再一次地明确这样的任务: 婆淮一步 问苏联学留，努力使我国在慗快时間队，接近和赶上 世界先淮水平。

我們要向苏联学替什么呢？虚心認地地学留荕联 的科学技街成就，这㷛是是必要和重要的，但僅是这 样的学桷还是不够的，我舸还必須淮一步向苏联虚心

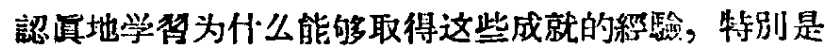
为什么能够在很快时間內从比較落后情况讯速赶上和

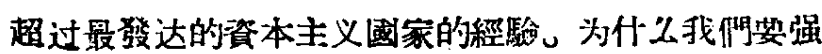

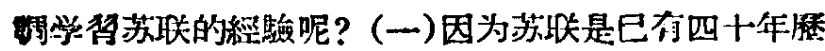
史的社会主义國家，苏联的經驗是最先淮的經驗。茄 联之听以能够迅速赶上和超过資本主义國家，主哭的 原因不能不就是: 社会寺义制度在科学技術和其他方 面对盗㶱主义㑬度具有然比的优越性。美國的著名科 学家尤雷和艾利邀最近就美國为什么在人造衙等方面 落后直接了当地說明了原因: 一因“卒卡錫主义”發

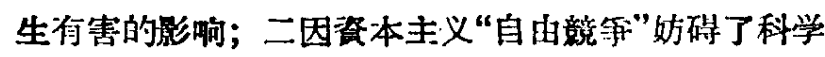
的發展。世界和平运动旗手、著名科学家約里奥一居 里也說: “西方國家一部分科学家在積做争取科学焦 步，但是由于政治原因，佰們济份進行科学创造的一 系列条件。”他还說: “苏联科学發展的日谷聕長是新社 会的發展規律。”因此我們裞，苏联發展社会主义.科学 事粪的經驗，对于我們这个基本上取得社会主义革命 勝利和正社淮行社会主义建設的國家，無疑是最任婆 的，是我们主要和首先妿学的。(二)苏联的經䮲不僅 是化淮的，而且是最全面、最完全的。芬联不僅佮靕 会主义革命的經驗，並且有社会主义建設的經驗，不

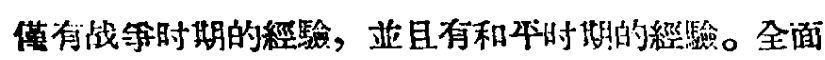
的、完全的綊驗，不僅是指证确的、成功的經驗，並 且包括有錯誤的、失敗的、走弯路的敩訓。我們中國 革命的經䮑，是比較丰富的，不僅有成功的經驗，並 且有犯錯器走等路、遭受过失敗的教訓，因此可以馀 是比較全面的、完全的。但在建設方面的經驗就做为 快之，开國只有八年，經驗是極不全面、梳不完全的。 苏联的成功經驗不僅可以帮助我們呾确前淮方问，即 是苏联走过弯路的教訓，也可以很好地給我們借鏿， 使我們少走弯路，所以我們必須要向苏联学相。（三） 苏联和我們是具有社会主义共同利分䄈礎和具有其同 前淮方向的兄弟友邦，只佮科会主义的友邦像茄联，

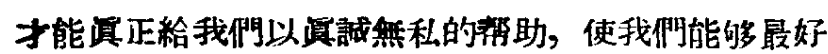
曼快地学到东西，这种渲誠無私的制助，景任何盗本 主义國家永远不可能做到的，因此我們必須要向湙联 学徣。

我們要向苏联学晳，紹不能媄会成为可以不向其 他兄弟國家学替了，这样的辟会当然是不对的。所有

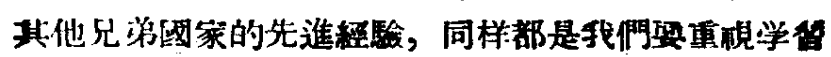

的，但是我們首先和主要的学替任务是向劳联学笪。 那末，社会主义陣营以外國家的經䐘就毫俱可学之处 䟚? 从來没份人这样說。凡是人家的对我們何用的东 西，我椚部是要问他們学替的。但是作为系統䅔捡，

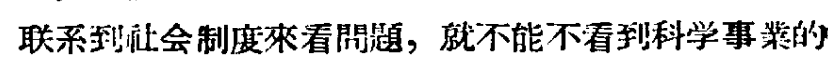
發展有着兩条根本不同的道路，一条是社会主义道路， 一条是凅本主义道路，忽碳这兩条道路的原则性区别 而去無原則地乱学，是慗犯錯誤的。

强調学盟苏联，不是自全國解放以來經常在这样

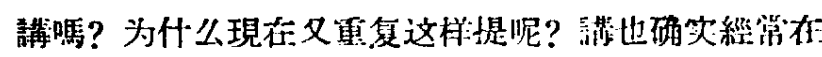

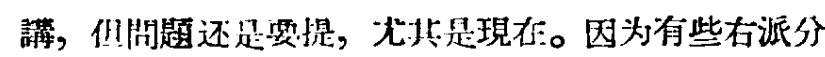
子在貶低满联科学技術成就的同时，朋目张胆地提出 反对向苏联学峺，最通行的惡青:手法，是加給我們一

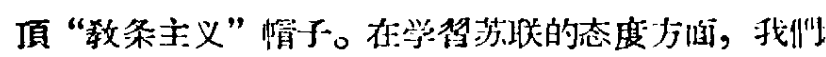
也哂为是有不同的：待的是实事求是的恣度，份分析 选擇，联系我國情兄，语于运朋，这是好的。但地确 有遠反实事求是的态度，探取教条声义的办法，不作 分析，不加选摆，不栚系实际，机晠硬套，这是不好

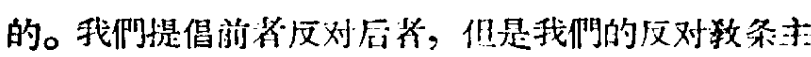
义的学相办法，和右派分子所提反对教条主义地学想 苏联是根本不同的。我們的目的是为了更好地向苏䶸 学習, 更善于向荕联学篔; 右派分子则是用反教条主:

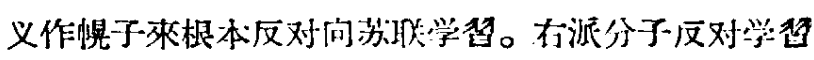

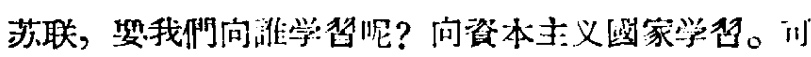

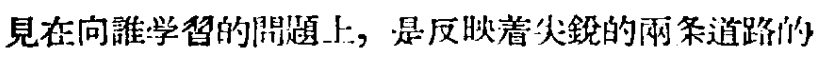

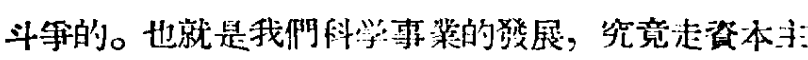
义的道路呢? 还是寺社会主:义的道路呢? 經过反有派

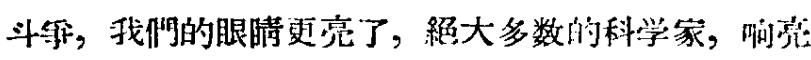
有力地反击了右派分子：我們要坚持走社会主义的道

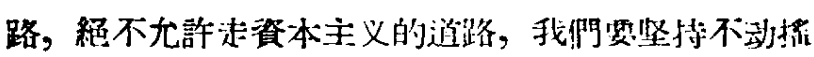

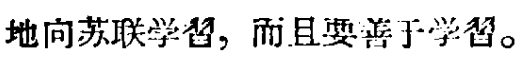

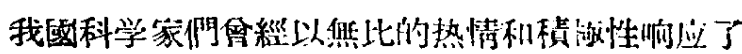

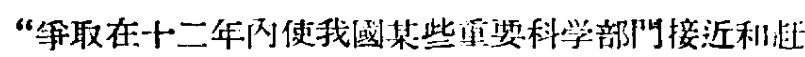
上世界先潐水平”的号名。但在去年下体年，好像勁 头有点不大了, 这一䦗題义不大被人們提起和重顽

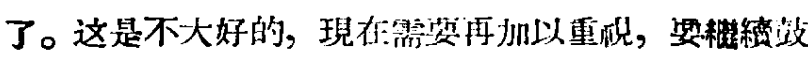

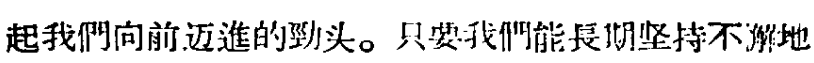
努力，褰于很好地向苏联学晳，这一个任务是一定能 侈实現的，一年來的实践已經大大塯留了我們在这方 面的信心。从最近苏咲人造地球衙星的成就和我圆反

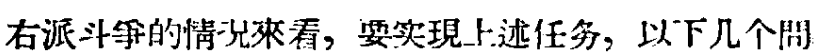
題是值得我們拄意的。

1. 加强科学研筑的全面計划性。我們的科学研究

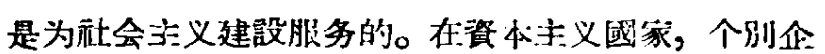
是有計划的，整体是無計划的，那种“自由韹孚” 妨碍了科学的更快的發展。在我們社会主义制度下， 可以实行全面規划，这就使我們有可能最合理!地欺备 
力量，能够取得最快的發展。計划性可以使科学家的 聚曼更好地与社会主义建設需要相結合，更好地發捧 其所長，而不妨的他們的專長的發揮。有些难以和或 家当前任务密切結合然而是很重要的探菜性工作，不 僅是允許的，而且也是同样要給以支持的。随着情况 的变化，尌划随时可以修改，因此計划是灵活的。苏 联貝格院士在慶视人造衛星發射成功时指出：代表人 类知識各方面的科学家的饇大集体在制造人造地球衛 星方面有計划地淮行工作，是实現人类自古以來的理 想的决定因素。去年我國科学家們已經以集体智慧制 訂了十二年發展远景規划，今年义進行了一系列的协 調工作。在这样的基礎上，再進一步地加强全面計划 性, 將会使我們的科学事業更迅速蓬勃地觔淮。

2. 加强領等。任何國家的科学事柴，都是有領望 的，問題是誰在領導。餈本主义國家的科学事栄是盗

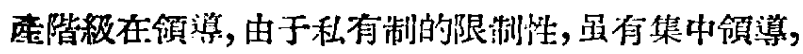
但分散性較大，然而不管是探取集中或分散的領導， 实質上都是領導科学研究为資本家的利经去服务。社 会主义國家的科学事学，勋由人人階級來領導，使科
学技術为人民服务。要加强动会声义科学事栗的計划 性，不加强領導是难以实現的。自从國务院科学規划 委員会成为常設机棈以后，一系列的协調工作逐步展 开，許多措施逐一实現，就是朋㙷的例证。

3. 建立强大的工人階級的科学豚伍。荕咲現在的 工程技術干部共有七十二万多人，相当于十月革命前 的九十倍。科学机关和高等学校的科学工作人員去年 就有二十四万人，几乎等于沙皇时代的二十四倍，他 椚中有一万多名科学博士和八万多名科学副博士。这

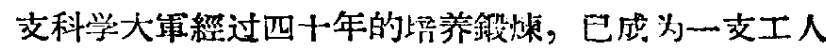
階級的具有高度政治覚悟和科学技術水平的大等，有 了这支科学大軍,就能接速不断政克科学堡亚，杽登科 学高峯。我們中國也要努力建立一支这样的工人階級 的科学大電,老的科学工作者要加虽思想改涉，成为工 人階級的科学冢，同时要培养新的大批的工人階級科

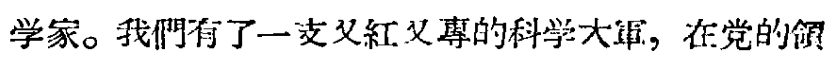
盤一下，按照計划去努力，一定能够在較短时間內实現 接近和赶上世界水平的任务，关于这一点，我們是洋 怀信心的。

\section{苏联在物理学上的輝煌成就}

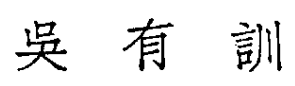

（中國科学院副院唇）

在偉大的十月社会主义革命后的四十个年中，苏

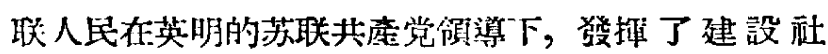
会主义的積例性，忘我地劳动着，把自己的祖國从筫 第落后的线罗斯帝國改变成为一个繁荣富强的桜新的 唒会主义國家。在馬克思列寧主义指導下所建立起來 的苏維埃社会主义共和國联照，到今日在全世界范園 们政治上是最民主的，經济上是最繁荣的，人民生活 是最幸䈏自由的，而且在科学技術成就上也是世界上 最先淮最發达的。

茫联的科学家在最近几年來一次义一次地㓣造出 奇跡，霹动了全世界人民的心，为苏联的科学成就俑 欢欣豉舞。

苏朕于1954年建成世界上第一个原子能發电站， 首創了和平利用原子能的光煰典范。巨型喷气客机 “四-104”的出現是苏联以最新貲气技術为人类 蚢行服务的起点。1947年荕联就开㕸用火简來研究大 乞上屡，獲得了100 公里高空大气厤的資料。今年八 月苏联宣布洲际彈道導彈試驗成功，使帝國主义者們 陷入警惶失措的境地。不久以前苏联發射了世界上第 一个人造衞星，开辟了星际旅行的涂仾，使人类的文 明躍進到一个新的廣閏無限的天地里。这一系列巨大
的成就都是建筑在各門基䃈科学和多种多样的实用技 術的廣大坚实的基礎之上的。

和其他学科一样，四十年來苏联的物理学仼着光 辉的成就。我們怀着十分兴奋的心情，借此幔祝十月 革命四十䓢年紀念的机会，就所知道的来談一淡苏块 在物望学上的成就和对我國的無私排助。我們必須以 苏联为搒样，必須淮一步加强向茄联的学晳。

举世皆知，苏联在和午利用原子能上有着侮其耀 煌的成就。自然, 苏联物理学家們对于作为和平利用 原子能基礎的一門学科—原子核物理—也有着酒 其光辉的幊献。苏联在第二次捗界大战之前就能完全 独立地开展重核鍕式分裂反应的研究。苏咲在1949年 所建立的第一个鈾一石墨反应堆也是欧洲第一个反应 堆。1954年苏联建成了世界上第一个原子能發电站。 事实說朋苏联在这方面已过在世柴先淮科学的前列。 原子反应堆资先是解放和控制原子能的第一步，其次 可以被利用來制造超金时元素和放射性同位素，研究物 算在輻照下的性筫，以及关于中于和物質的相互作用 諸問題。在一系列头等重要的理諭和实际問題上，苏 联的原子反应堆起了巨大的难以估量的作用。

苏联在原子核物理研究中号一个主要方面就是由 